\title{
Tres Torres y un mar: La última obra de Fernando Cassinello
}

\section{Three Tower and a sea: The last work of Fernando Cassinello}

\author{
J. F. García-Sánchez ${ }^{(*)}$
}

\section{RESUMEN}

La obra del arquitecto almeriense Fernando Cassinello Pérez ha sido escasamente publicada, pero lo cierto es que construyó mucho y bien. Su vida descansa sobre tres pilares: la producción arquitectónica, la actividad académica y la inquietud investigadora. Aquí se expondrá su última obra: las Tres Torres trillizas Star-Building (1975) que construyó frente al Paseo Marítimo de Almería, en el barrio de El Zapillo; y que son un elegante ejercicio residencial de investigación formal y sinceridad estructural. También son un ejemplo de cómo, desde la renuncia y con una densidad moderada, es posible construir interesantes propuestas de viviendas -orientadas al turismo- en la primera línea de playa. Y que, desde luego, merecen ser conocida por quien decida hoy proyectar y construir arquitectura colectiva. Se analizarán y describirán las tres versiones del proyecto; y se explicará cómo la estructura y las huellas del proceso de construcción son la génesis y el argumento de esta obra.

Palabras clave: Cassinello; estructura; hormigón; construcción; torre; proyecto; Almería.

\section{ABSTRACT}

The work of spanish architect, Fernando Cassinello Pérez has been rarely published, although he built a lot and well. His life is based on three areas: architectural production, academic and research activities. In this research his latest work will be discussed: Three Tower triplets Star-Building (1975) was built on the seafront in Zapillo, Almería; and that is a smart residential work of formal investigation and structural sincerity. Star-Building is an example of how, since the resignation and moderate density, it is possible to construct interesting proposals for housing -oriented towards tourism- on the beachfront. Of course, it deserves to be well known by who nowadays decides to design and build collective architecture. The three project versions will be discussed and described, also explaining how the structure and the traces of the process of building are the genesis and story of this work.

Keywords: Cassinello; structure; concrete; construction; tower; project; Almería.

(*) ETS de Arquitectura y Edificación - Universidad Politécnica de Cartagena (España).

Persona de contacto/Corresponding author: josefrancisco@coaalmeria.com (J. F. García-Sánchez)

Cómo citar este artículo/Citation: García-Sánchez, J. F. (2014). Tres Torres y un mar: La última obra de Fernando Cassinello. Informes de la Construcción, 66(536): e047, doi: http://dx.doi.org/10.3989/ic.14.013.

Licencia/License: Salvo indicación contraria, todos los contenidos de la edición electrónica de Informes de la Construcción se distribuyen bajo una licencia de uso y distribución Creative Commons Reconocimiento no Comercial 3.o. España (cc-by-nc). 


\section{INTRODUCCIÓN: ARQUITECTURAS OLVIDADAS}

La obra del arquitecto Fernando Cassinello Pérez (Figura 1) (Almería, 1928-Madrid, 1975) ha sido escasamente publicada; y, por ello, corre el riesgo de caer en el olvido, como tantas otras obras de arquitectos que, debido a su intensa actividad profesional, descuidaban la difusión de su propia arquitectura. La actividad docente en la Cátedra de Construcción de la Escuela de Arquitectura de Madrid, su inquietud investigadora desarrollada en el Instituto Eduardo Torroja (1), así como su voluptuosa personalidad eclipsaron, de algún modo, su producción arquitectónica. Pero lo cierto es que construyó mucho y bien; sobre todo en su ciudad de origen: Almería. Allí mantuvo su estudio en la entreplanta del número 2 de la Avenida de la Estación esquina con la Rambla Belén; además de otro estudio Madrid. Y es en la ciudad andaluza donde construye emblemas locales destinados a dar servicio a las demandas turísticas y de la industria cinematográfica, como el Gran Hotel de Almería (1967) (2) (3), el Hotel Alcazaba de El Zapillo (1968) -convertido después en Residencia y derribado definitivamente en 2006- o las cuevas del Mesón Gitano, a los pies de la Alcazaba: punto de encuentro obligado para los actores que rodaban en el paisaje almeriense y cobijo bajo tierra donde disfrutar del flamenco local. Aunque es la vivienda, colectiva y aislada -libre y protegida- el campo donde desarrolla ampliamente su actividad profesional. En Aguadulce tiene la posibilidad de construir interesantes edificios de apartamentos, como los conocidos El Palmeral (1968) (4).

La obra de Fernando Cassinello se puede acomodar en la segunda generación del Movimiento Moderno: amparada en la racionalidad funcional y con cierto aire brutalista, donde la estructura empezaba a preocupar, siendo, en muchos casos, la génesis y el argumento del proyecto; introduciéndose, también, en proyectos de vivienda. Se empieza a prestar atención al lugar: no sólo físico o geográfico, sino también emocio- nal, económico y cultural. La arquitectura de Cassinello es Universal, pero también mediterránea y local: celosías que traspiran luz, lugares intermedios, terrazas que miran al mar. Todo ello concebido con el apoyo de materiales y técnicas locales que construyen atmósferas que reconcilian el placer con la austeridad.

La obra que nos ocupa, las Tres Torres Star-Building (1975) (Figura 2) frente al Paseo Marítimo de Almería, son un elegante ejercicio residencial de investigación formal y sinceridad estructural. Y son un ejemplo de cómo, desde una densidad moderada, es posible construir interesantes propuestas de viviendas colectivas -orientadas al turismo- en la primera línea de playa, en un tiempo donde la ausencia de normativas protectoras y la voracidad especulativa, empezaba ya a colmatar la costa. Y, a pesar de estas virtudes, el Star-Building ha sido olvidado por las guías de arquitectura local y regional; así como por aquellos que hacían constar las arquitecturas modernas en registros nacionales. Pero si uno se detiene con atención, advierte en esta obra periférica valores que la convierten en un interesante ejemplo de Arquitectura. Y, desde luego, merece ser conocida por quien decida hoy proyectar y construir arquitectura colectiva.

\subsection{Referencias}

Las únicas referencias existentes sobre las Tres Torres del Star-Building las encontramos en su monografía: Construcción hormigonería (5) cuya edición (1974) coincide con la fecha de construcción de la obra que nos ocupa (1975). En el capítulo 10, dedicado a los «Encofrados» (p. 197) aparece una fotografía donde reza: «Encofrado de superficies horizontales: colocación de puntales y sopandas». En ella se puede ver una imagen parcial de una de las torres, previsiblemente el forjado del techo de la planta baja, apuntalado mediante unos rudimentarios rollizos de madera. En el capítulo 11 titulado «Hormigones vistos» (p. 273) ilustra el epígrafe Hormigones blancos con dos fotografías, en cuyo pie se puede leer:

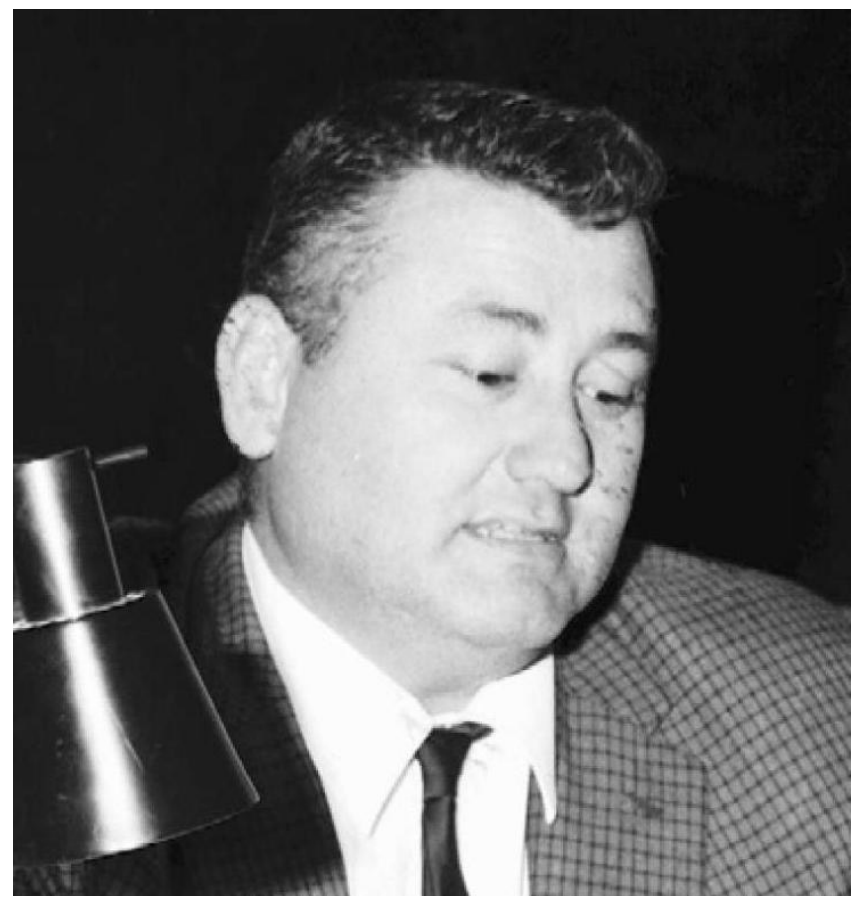

Figura 1. Fotografía de Fernando Casssinello (Fuente: Instituto de Ciencias de la Construcción Eduardo Torroja).

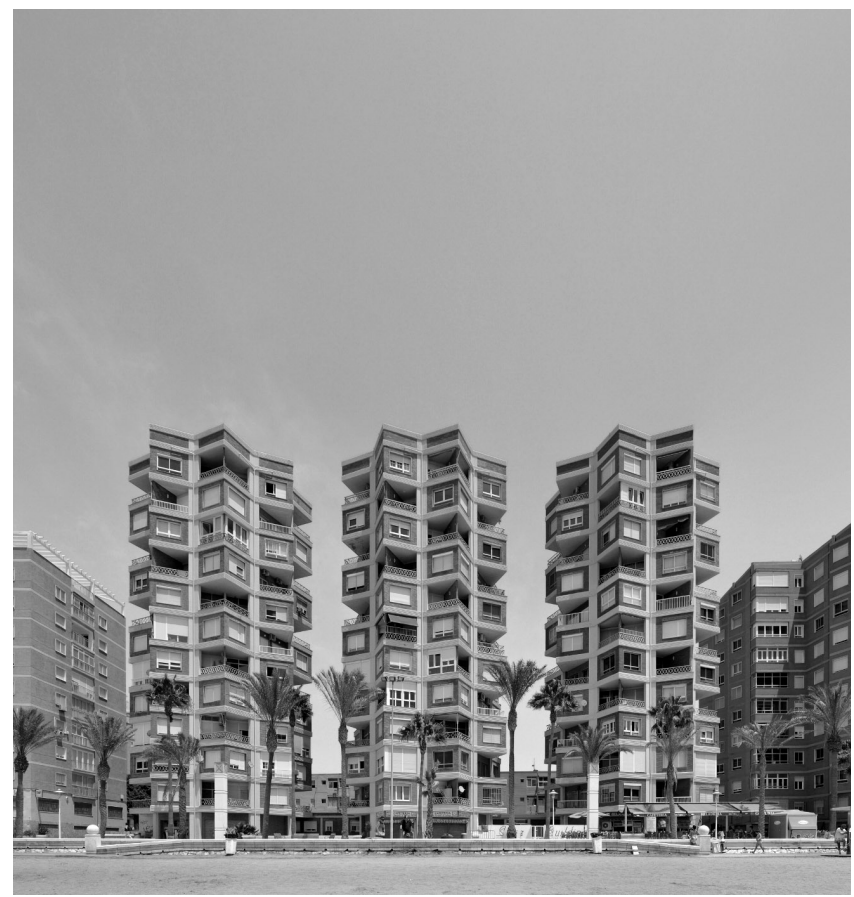

Figura 2. Fotografía, desde el mar, de las Tres Torres Star-Building. Fotografía: JFGS. 
«Hormigón blanco en pilares y vigas encofrados con chapa metálica plegada, "Star Building" Arquitecto: F. Cassinello». En estas fotos -donde sí señala quién es el arquitecto así como el nombre de la obra- se muestra un estado más avanzado de ella, haciendo hincapié, esta vez, en los forjados y pilares: elementos estructurales ejecutados en hormigón de color blanco ${ }^{1}$ y que quedarán vistos, tal y como se aprecia en la (Figura 2).

El periódico La Voz de Almería del domingo, 1 de septiembre de 1974, publica un anuncio a toda página donde la empresa promotora SANFER ${ }^{2}$ anuncia que ya es posible visitar el piso piloto del Star-Building. En el anuncio se puede ver, desde el mar, una lejana imagen de todo el frente marítimo de El Zapillo. Y en otra, más cercana, se advierten las torres todavía en construcción en las plantas superiores.

\section{SITUACIÓN: LA PERIFERIA DE LA PERIFERIA}

Las Tres Torres Star-Building se sitúan sobre un solar rectangular de $60 \times 20$ metros en el barrio de El Zapillo en Almería (Figura 3 y 4), cuya fachada principal mira al Paseo Marítimo y a ese Mar Mediterráneo que las justifica de suelo a techo. Desde ahí, también es posible ver el Cabo de Gata y Aguadulce, así como al Puerto de la Ciudad. Se trata, por tanto, de una panorámica de 180 grados -que la propia geometría de las torres favorece- sobre la Bahía de Almería.

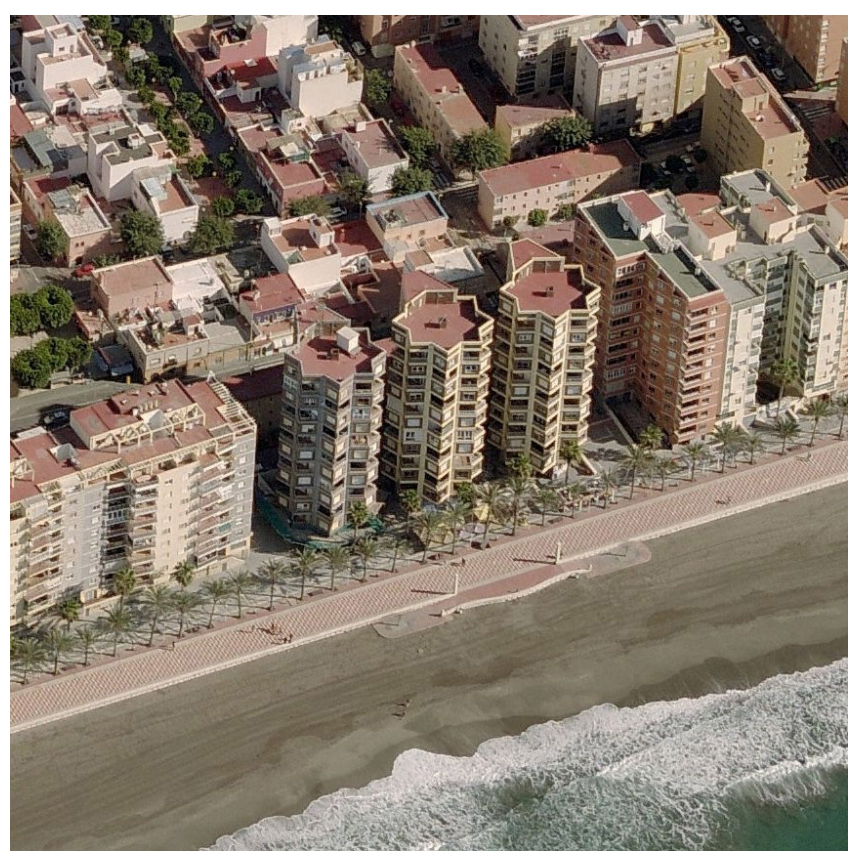

Figura 3. Imagen aérea de las Tres Torres Star Building. (Fuente: Google Maps).

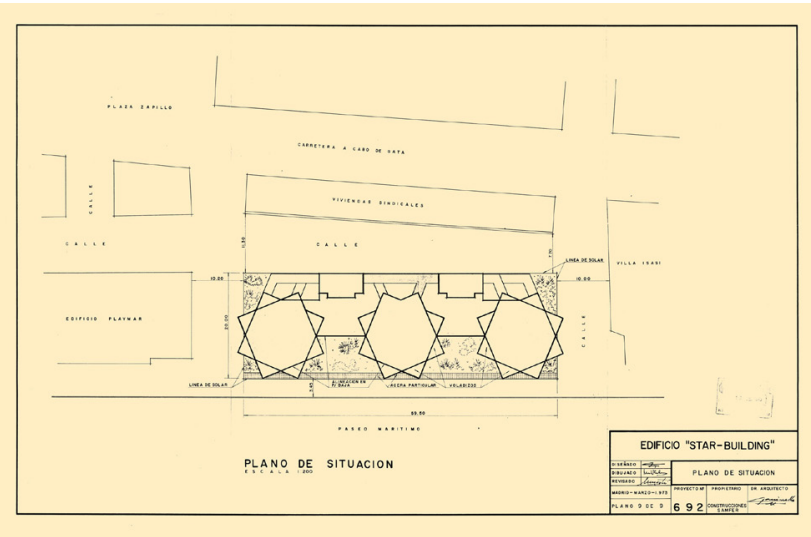

Figura 4. Plano de Situación de las Tres Torres Star Building (primera versión).

(Fuente: Archivo Municipal del Ayuntamiento de Almería).

Aunque existen dos accesos que, en su planta baja, unen las Tres Torres directamente con la playa, la entrada principal se produce por detrás: la Calle Costa del Sol es una modesta vía paralela a la Avenida de Cabo de Gata, ésta sí, una importante arteria que sirve de límite al Sur de la Ciudad Jardín (19401947) (6) y que atraviesa de poniente a levante el barrio de El Zapillo. Esta vía, que antes fue camino, une el centro consolidado de la ciudad con el aeropuerto, la Universidad (7), las playas del Levante y Cabo de Gata. Aunque la situación actual del Star Building sea algo más interior, en el momento de construcción supuso -al igual que El Zapillo- la nueva periferia de la ciudad.

Por su condición topográfica, la ciudad de Almería ha ido creciendo hacia el norte y, sobre todo, hacia levante: primero con el ensanche de Altamira, al otro lado de la Rambla; y, después, colonizando la vega, al otro lado de las vías del tren hasta casi llegar a la desembocadura del Río Andarax. Y, desde luego, la franja que quedaba sin construir entre la Ciudad Jardín (1940-1947) y el mar: que es donde se levantan las Tres Torres del Star-Building (Figura 4).

Se sitúa, por tanto, en la periferia de una ciudad periféri$c a$. El compromiso y servidumbre estilísticos que supondría construir en el centro -geográfico y cultural-, queda totalmente liberado en esta obra que, por su situación exterior, permitía la exploración formal y valentía expresiva que en ella desarrolla el arquitecto Fernando Cassinello.

\section{RENUNCIA: VIVIR JUNTOS (Y SEPARADOS)}

Renuncia es la primera palabra que aparece en la memoria de construcción ${ }^{3}$ del proyecto Star-building. Según las Ordenanzas Municipales, el volumen máximo autorizado era de $15 \mathrm{~m}^{3} / \mathrm{m}^{2}$, siendo en este caso el volumen total autorizado ${ }^{4} \mathrm{de}$ $37.530 \mathrm{~m}^{3}$; sin embargo, se propone una solución que consu-

\footnotetext{
${ }^{1}$ En la actualidad, estos elementos estructurales - tanto pilares como forjados-, están pintados de color amarillo.

${ }^{2}$ Se trata de una errata del periódico: lo cierto es que el nombre de la empresa era SAMFER, que es el acrónimo formado por los apellidos de Mariano Samper y Antonio Vicente Ferrete, socios y promotores inmobiliarios almerienses de los años 60 y 70 , con los que el arquitecto Fernando Cassinello construyó varios proyectos.

3 En la memoria del Proyecto de Edificio «Star-Building» (proyecto número 692), Almería, Marzo, 1973, reza: «Para poder llegar a la solución proyectada, consistente en tres torres exentas de planta estrellada, ha sido preciso renunciar a muchos metros cúbicos de volumen edificable y a retraerse de las alineaciones oficiales, creando zonas ajardinadas. En las doce plantas de cada una de las tres torres, se distribuyen locales comerciales en planta baja, y dos viviendas de dos dormitorios por planta, lo que arroja un total de 66 viviendas».

${ }_{4}^{4}$ Como se ha comentado, las Tres Torres se asientan sobre una parcela de $1.200 \mathrm{~m}^{2}$, sin embargo, la propiedad disponía de un solar $2.502 \mathrm{~m}^{2}$, cediendo, la diferencia, a los viales laterales.
} 


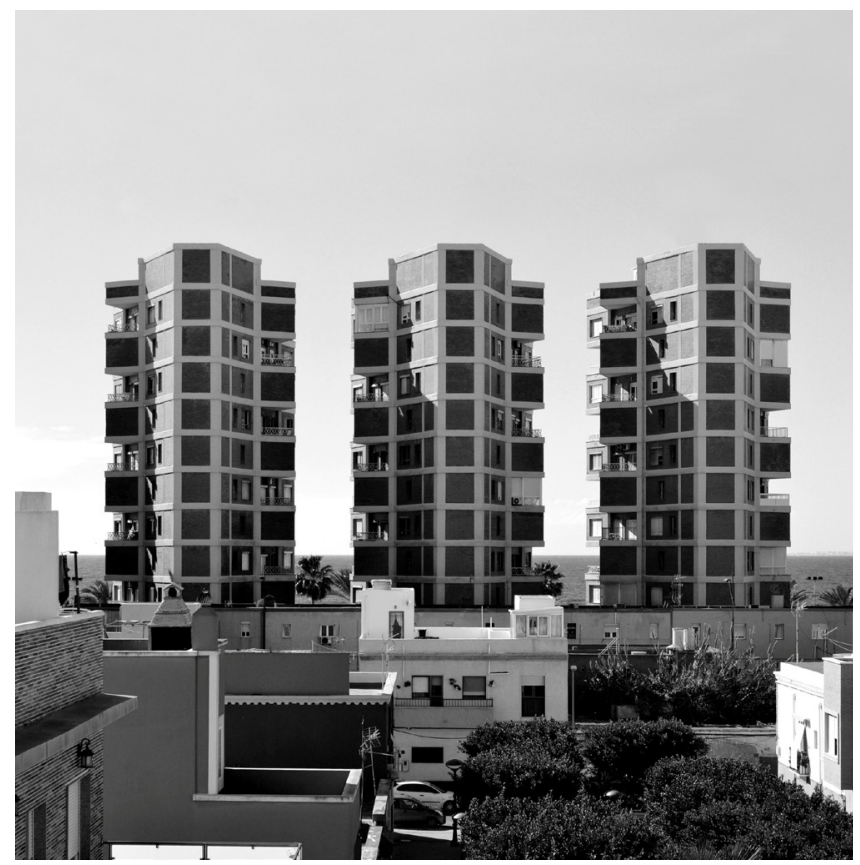

Figura 5. Fotografía, desde el barrio de El Zapillo, de las Tres Torres Star-Building. (Fotografía: JFGS).

mía $16.390 \mathrm{~m}^{3}$, de este modo se libera -se renuncia a construir- $21.140 \mathrm{~m}^{3}$.

Se huye, por tanto, de un único volumen pesado que, por un lado ocultaría las vistas desde el interior del barrio hacia el mar (Figura 5) -tal y como ocurre con la mayoría de los edificios que han ido colonizando el frente marítimo en el barrio de El Zapillo-; y, por otro, se consigue un carácter singular, construyendo menos volumen del autorizado, y articulando éste en tres torres independientes: aunque como se desarrollará más adelante, en la primera versión del proyecto, las torres estaban comunicadas por un sistema de galerías. Por otro lado, renunciando a construir más, también se consigue huir de una alta densidad de personas y vehículos en una de las zonas residenciales que ya presagiaban un porvenir turístico, al estar situado frente al mar.

El resultado es un atractivo conjunto residencial formado por tres torres exentas y separadas -aunque unidas en su planta baja a modo de basamento-, con una densidad que es el fruto de construir 66 viviendas de dos dormitorios en un solar de $1.200 \mathrm{~m}^{2}$ de superficie (22 viviendas por torre, además de la vivienda del conserje en la planta baja).

Una de las lecciones que nos regala el arquitecto Fernando Cassinello en esta obra es la aceptación de la renuncia como una regla previa e ineludible para quien pretenda hoy proyectar y construir arquitectura. Retranquearse de los máximos y auto-imponerse unos márgenes nos reconcilia con la cortesía propia de quien sólo pretende especular con la calidad, haciendo del aire no construido un argumento proyectual. Construir menos y mejor es más sostenible.

\section{FIRMITAS O LA ESBELTEZ. LAS TORRES TRILLIZAS}

Conquistar las nubes, levantando un menhir, es una antiguo anhelo del hombre; y un mecanismo antropológico para advertir de nuestra presencia en el paisaje. La idea de erigir una atalaya que se convierta en símbolo de progreso, desarrollo y poder, está grabada a fuego en la piel de todo arquitecto.

El 4 de junio de 1974, unos meses antes de concluir el proyecto de Almería, Fernando Cassinello envía al promotor del Star-Building una postal de las Torres Gemelas desde NYC, donde reza: «El próximo edificio tenemos que hacerlo más grande que éstas ilas más grandes del mundo! Abrazos» (Figura 6). Lo cierto es que él no construyo (dos) Torres Gemelas, sino (tres) Torres trillizas, pero en Almería.

En general, toda torre tiene el afán de tocar el cielo, siendo la más alta de todas las torres construidas: o al menos parecerlo. Y para ello, encuentran en la esbeltez ese lugar común adonde acudir. Las Tres Torres Star-Building de Almería, con sus 12 niveles, no son excesivamente altas. Y sin embargo, consiguen parecerlo mediante una serie de mecanismos arquitectónicos y formales: 1) La pequeñez de la planta: se trata de una planta con sólo dos viviendas, de $77,51 \mathrm{~m}^{2}$ útiles por casa. 2) Todos los pilares -desde el primer suelo hasta el último techo- tienen la misma dimensión, reforzando así la apariencia vertical. Por tanto, delegan en el armado la capacidad de resistir los esfuerzos según el caso y la planta. También el hecho de que la estructura de hormigón se manifieste en el exterior -tanto los pilares como las vigas de borde-, que éstos sean estriados y que su color destaque respecto a los paños de ladrillo cerámico del cerramiento subrayan su condición vertical. 3) La composición de la planta que, al estar giradas unas respecto de las otras -las pares respecto de las impares- dejan a las puntas de las estrellas en voladizo,
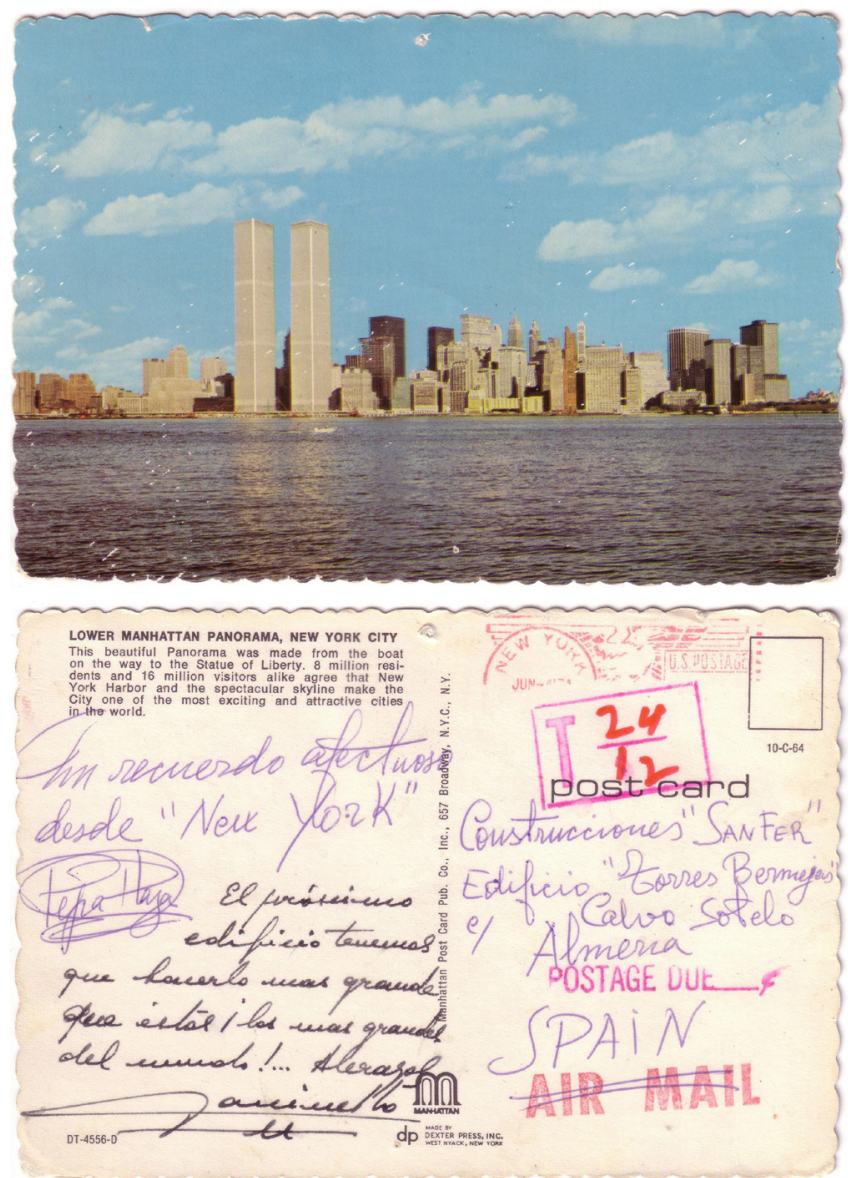

Figura 6. Postal enviada, desde NYC, por Fernando Cassinello al promotor Mariano Samper, 4 de junio de 1974. (Fuente: María del Mar Samper). 
desmaterializando el perímetro y disminuyendo aún más la percepción del tamaño de la planta, al advertirse masas de aire entre las terrazas. Lo cierto es que, aunque las puntas de la estrella sobresalen, esta obra no busca en el forjado el elemento que vuele: sino en los cuerpos volados construidos de las plantas. Éstos sobresalen, en una punta de la estrella sí, y en otra no. Y dan lugar a terrazas triangulares cubiertas, en cuyo techo existe el cuerpo volado y cerrado de la vivienda superior, y que se apoyan en otro exactamente igual, pero de la planta inferior. Este juego permite reducir aparentemente la planta, reduciendo el verdadero contorno de la Torre al perímetro virtual del octógono al que se apoya en la intersección común que resulta de girar dos cuadrados $45^{\circ}$. Esos voladizos se aprovechan bien para espacios interiores habitados; o bien para terrazas exteriores pero cubiertas-. 4) El alzado posterior: la geometría de la escalera (Figura 5) permite que el alzado posterior mida sólo 3,50 m de longitud, y se eleva, sin embargo, toda la envergadura de la torre.

Se trata, en resumen, de desmaterializar el perímetro de la estrella: haciéndolo volar y reduciendo la planta; e intentar subrayar la verticalidad manifestando la estructura en el exterior. El arquitecto Fernando Cassinello consigue, a través de estos mecanismos, conquistar definitivamente la esbeltez.

\subsection{Estructura}

La estructura presenta en el exterior 8 pilares con forma de «V» obtusa (Figura 7) -formando los lados de la «V» un ángulo de $135^{\circ}$ (suplementario del ángulo $45^{\circ}$ que se usa para girar las plantas entre sí)- cuya dimensión es de $50 \mathrm{~cm}$ medidos desde el vértice interior hasta el extremo, y $25 \mathrm{~cm}$ de canto (Figura 8). Los pilares, al igual que los forjados, están construidos de hormigón armado, empleando para su construcción, un encofrado «estriado». Estos pilares se disponen en las intersecciones que forman los dos cuadrados girados $45^{\circ}$ que son el germen de la planta (Figura 8). Y su forma de «V» obtusa de $135^{\circ}$ se apoya, de forma natural, sobre la geometría de la estrella de ocho puntas o estrella tartésica. Si se prolonga una línea virtual desde cada una de las uniones

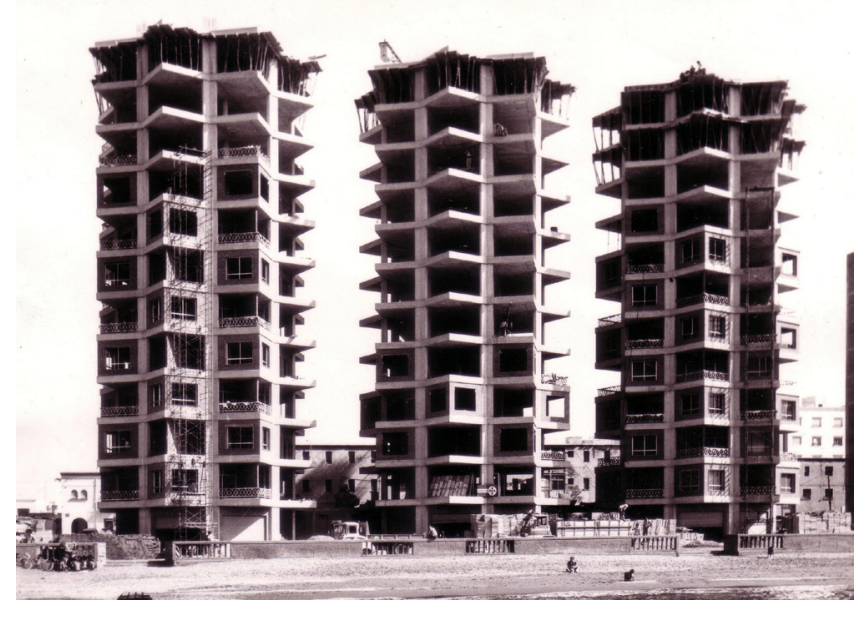

Figura 7. Imagen, todavía en construcción, de las Tres Torres del Star Building, año 1974. (Fuente: María del Mar Samper).

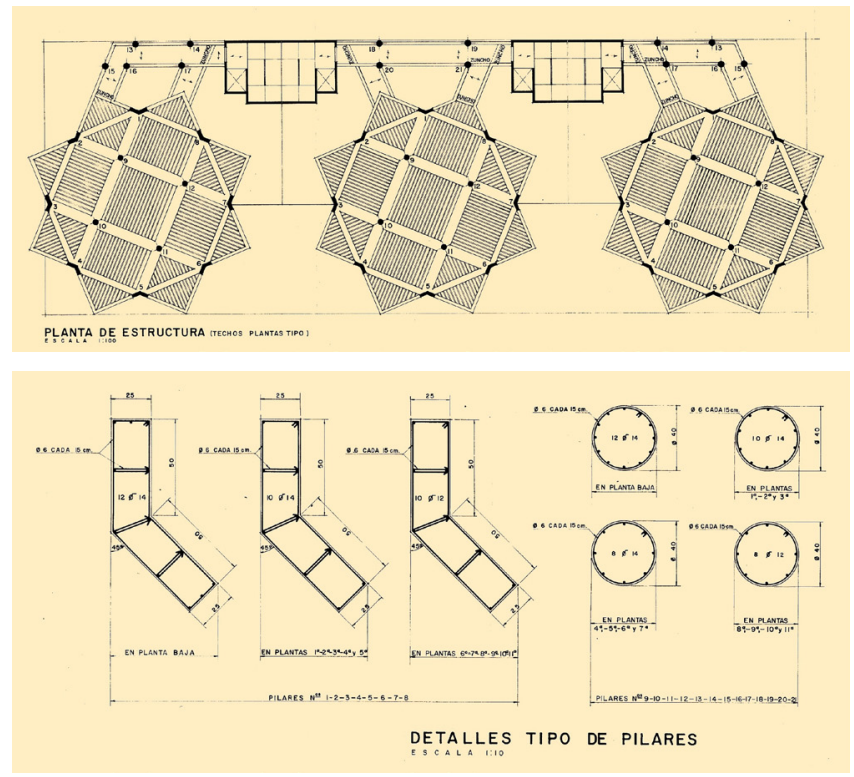

Figura 8. a) Planta de la estructura de las Tres Torres del Star Building (primera versión).

(Fuente: Archivo Municipal del Ayuntamiento de Almería).

b) Detalle tipo de pilares de las Tres Torres del Star Building (primera versión).

(Fuente: Archivo Municipal del Ayuntamiento de Almería).

de éstos, con los del lado opuesto de su mismo cuadrado -y se repite esta operación con el otro de los lados del mismo cuadrado- se forma una parrilla de cuatro líneas imaginarias en cuyas intersecciones descansan los 4 pilares de sección circular y $40 \mathrm{~cm}$ de diámetro que encontramos en el centro de la planta de cada torre; construidos éstos de hormigón armado y liso.

En la zona de la escalera y ascensor se disponen dos pilares en el extremo norte ${ }^{5}$, también con forma de «V» e idéntica dimensión que sus semejantes del perímetro de las torres; la estructura presenta también otros dos pilares de sección cuadrada de $30 \mathrm{~cm}$ de lado, en cada uno de los tres núcleos verticales. Además del resto de pilares que soportan la planta baja -entre las torres-, de sección rectangular de $40 \times 25 \mathrm{~cm}$.

Las vigas y jácenas están dibujadas sobre los dos cuadrados girados (Figura 8), y la parrilla de líneas centrales descrita anteriormente -al igual que los pilares, construidas de hormigón armado habiendo empleado para su construcción un encofrado «estriado» en las caras exteriores de la fachada- Los forjados son planos y unidireccionales -ejecutados in situ y desencofrados en su cara inferior con una textura irregular (Figura 9) - y que quedarán vistos en los techos del interior de las viviendas. En la planta baja -el basamento- el techo de hormigón armado está igualmente desencofrado dejando la huella de las tablillas de maderas, esta vez dispuestas longitudinalmente; igual ocurre con las caras inferiores de las zancas de las escaleras y los descansillos distribuidores de las viviendas.

Las vigas de borde de $60 \mathrm{~cm}$ de canto se elevan por encima del forjado anticipando el peto de las terrazas. La dirección de forjado es centrífuga: salvo el paño central que se acomo-

\footnotetext{
${ }^{5}$ Aquí se hace referencia al proyecto que finalmente se construyó, donde existían tres núcleos de escaleras, y que más adelante se titula «tercera versión» (apartado 5-3, Figura 13).
} 


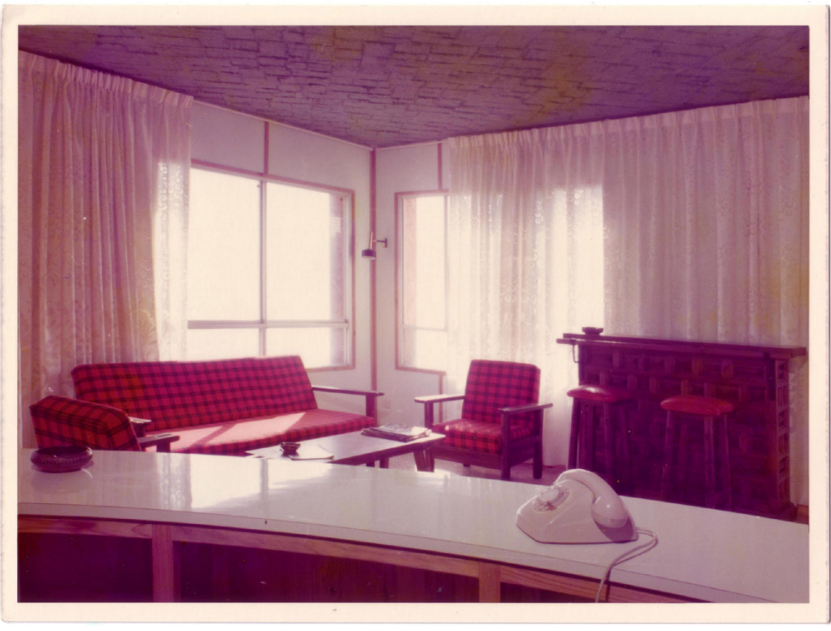

Figura 9. Fotografía del Estar-Comedor, donde se aprecia la textura del techo. Piso-piloto de las Tres Torres del Star Building (1975). (Fuente: María del Mar Samper).

da a una de las direcciones (Figura 8). La escasa capacidad portante del terreno -arena compacta y $1 \mathrm{~kg} / \mathrm{cm}^{2}-$ obligaron a resolver la cimentación mediante una losa nervada (unas «T» invertidas), de cuyos cruces de vigas arrancan los pilares.

Nos encontramos, por tanto, ante una estructura lógica y sincera, que sólo se permite la licencia de mantener la sección de los pilares en todas las plantas, delegando en el armado, la responsabilidad de resistir los esfuerzos según el caso y la planta. Una estructura que busca la belleza en la sobriedad que desprende el proceso constructivo, recibiendo con agrado las huellas que la construcción imprime durante el proceso, exhibiéndolas como un triunfo: «El hormigón se afana por encontrar su expresividad mostrando orgulloso su textura, color, irregularidades del encofrado que le dio forma, rugosidades y defectos de su naturaleza pétrea,...» (8).

\subsection{Cerramiento. El amigo del ladrillo}

«Hace bastante tiempo pronuncié una conferencia, cuyo título Los amigos del ladrillo era suficientemente expresivo de mi partidismo por los materiales cerámicos. Y es que en verdad, resulta asombroso, que no se haya encontrado aún ningún material de construcción capaz de quitar a los materiales cerámicos su papel preponderante. La arcilla cocida, que tan brillantemente se comportó a lo largo de su historia, y pese a sus miles de años de existencia, muestra hoy la juventud y lozanía de los materiales más novedosos» (9). Estas palabras las pronunció Fernando Cassinello el 29 de abril de 1959, durante una conferencia en el seno del XII Coloquio Técnico, organizado por el Instituto Técnico de la Construcción y el Cemento. Allí definió al ladrillo como «paralelepípedo de piedra artificial -generalmente de arcilla cocida-, manejable con una sola mano» (10). El título de la conferencia advierte de su interés sobre el material cerámico; y en su definición presagia la relación antropológica del ladrillo con la mano del hombre. Su disposición en obra, uno a uno, celebra esa sobria imperfección, que lo hacen un buen compañero de viaje del hormigón. Un muro de ladrillo pertenece a quien lo levantó. Y nunca habrá dos muros iguales.

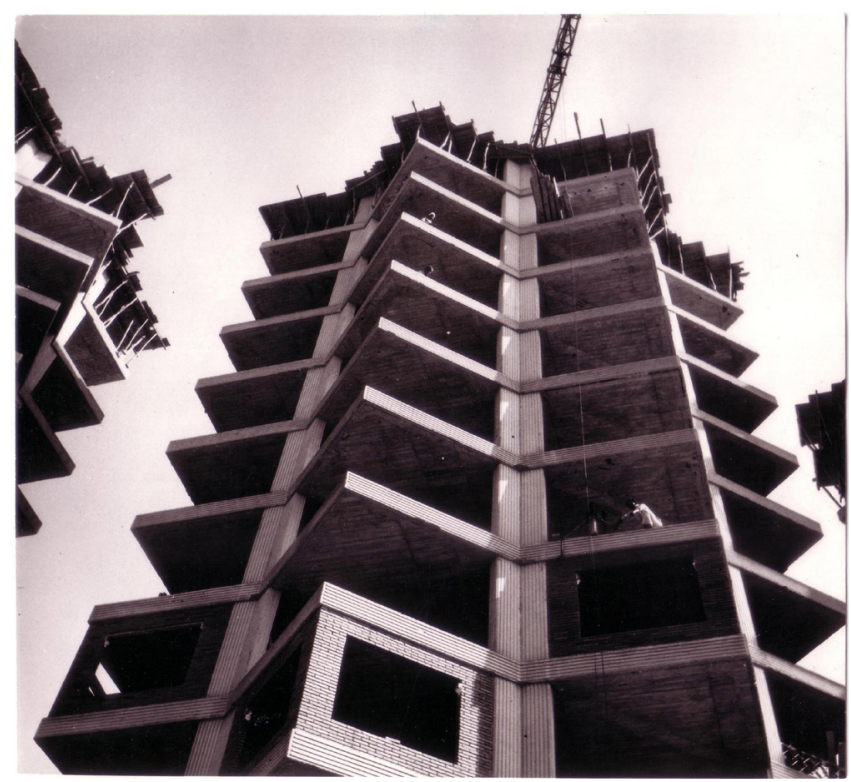

Figura 10. Imagen de la construcción de las Tres Torres del Star Building, año 1974. (Fuente: María del Mar Samper).

Todos los cerramientos del Star Building están construidos de ladrillo perforado cara vista de color tierra cuyas dimensiones son $25 \times 12 \times 5 \mathrm{~cm}$; siendo el aparejo a soga con juntas horizontales y verticales de $1 \mathrm{~cm}$ (Figura 2 y 10). También lo están los cerramientos exteriores de las viviendas en su contacto con los descansillos del ascensor; al igual que el muro que separa la terraza principal de las dos viviendas.

\section{UTILITAS O EL ORDEN: ESTRELLA TARTÉSICA}

Como se ha comentado, la idea fundamental del proyecto reside en haber adoptado una planta estrella de ocho puntas o estrella tartésica ${ }^{6}$-octógono regular estrellado- para cada una de las torres; además de considerar giradas las plantas pares respecto a las impares, un ángulo de $45^{\circ}$. Esta geometría se mantuvo desde los albores del proyecto: es en la disposición de los núcleos de comunicación donde se encuentran las diferencias. Existen, al menos, tres versiones del proyecto.

\section{a) Primera versión: pasarelas}

La primera de las versiones contaba con dos núcleos de comunicación vertical (Figura 11) -con dos escaleras y dos ascensores cada núcleo- situados al norte, entre las torres; y un sistema de galerías para llegar hasta ellos desde las puertas de los apartamentos. Lo ventajoso de esta primera versión con la que comenzó a tramitarse el expediente municipal en 1973- era el hecho de mostrar a la estrella de ocho puntas por completo alrededor de toda la torre. Sin embargo, el sistema de pasarelas, interfería las vistas y, desde el Zapillo y el mar, se deshacía la voluntad de construir tres torres exentas; asunto éste que se resolvió en la solución definitivamente construida. Tampoco existía, en esta primera versión, ese interés en mostrar la estructura -pilares y forjados-.

La planta está compuesta de dos viviendas de dos dormitorios. Siempre fue así. A los apartamentos se accede desde la parte

\footnotetext{
${ }^{6}$ La estrella Tartésica o de Salomón también es conocida como estrella de Abderramán I, primer califa de al-Ándalus, quien la popularizó por todo el Mediterráneo, África y Europa.
} 


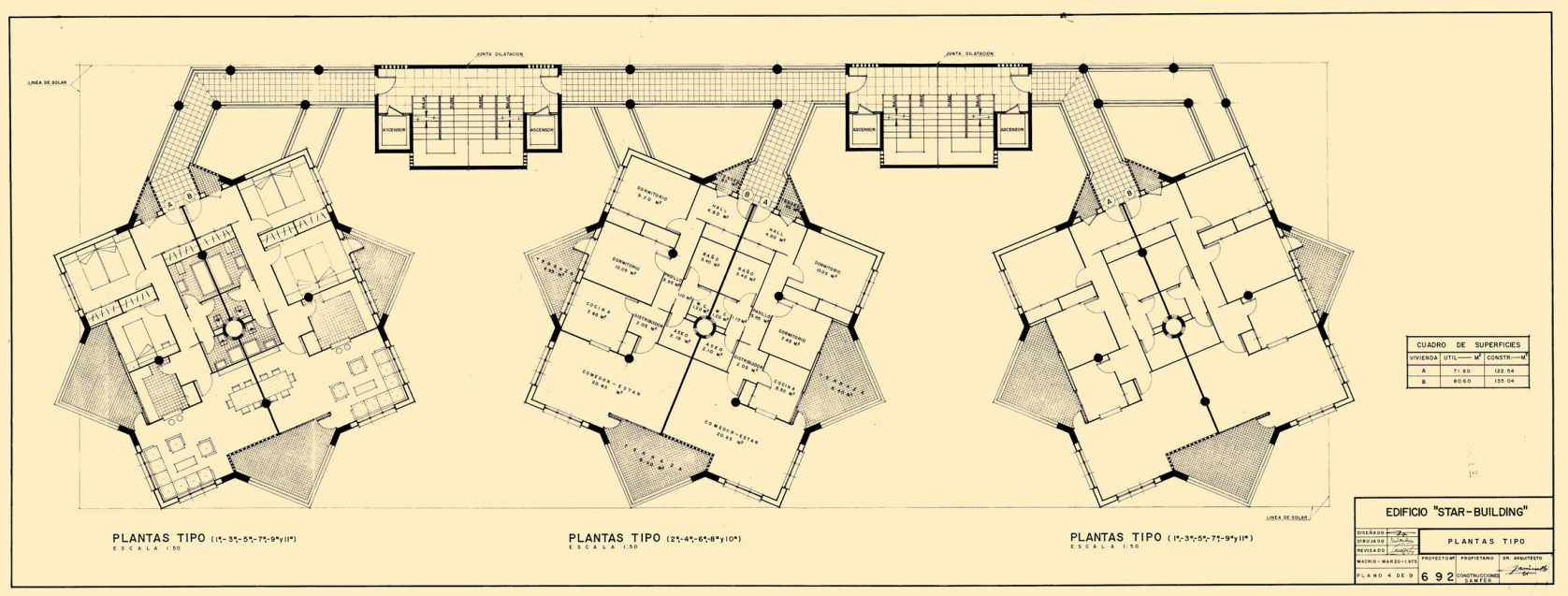

Figura 11. Planta tipo de las Tres Torres del Star Building (primera versión). (Fuente: Archivo Municipal del Ayuntamiento de Almería).

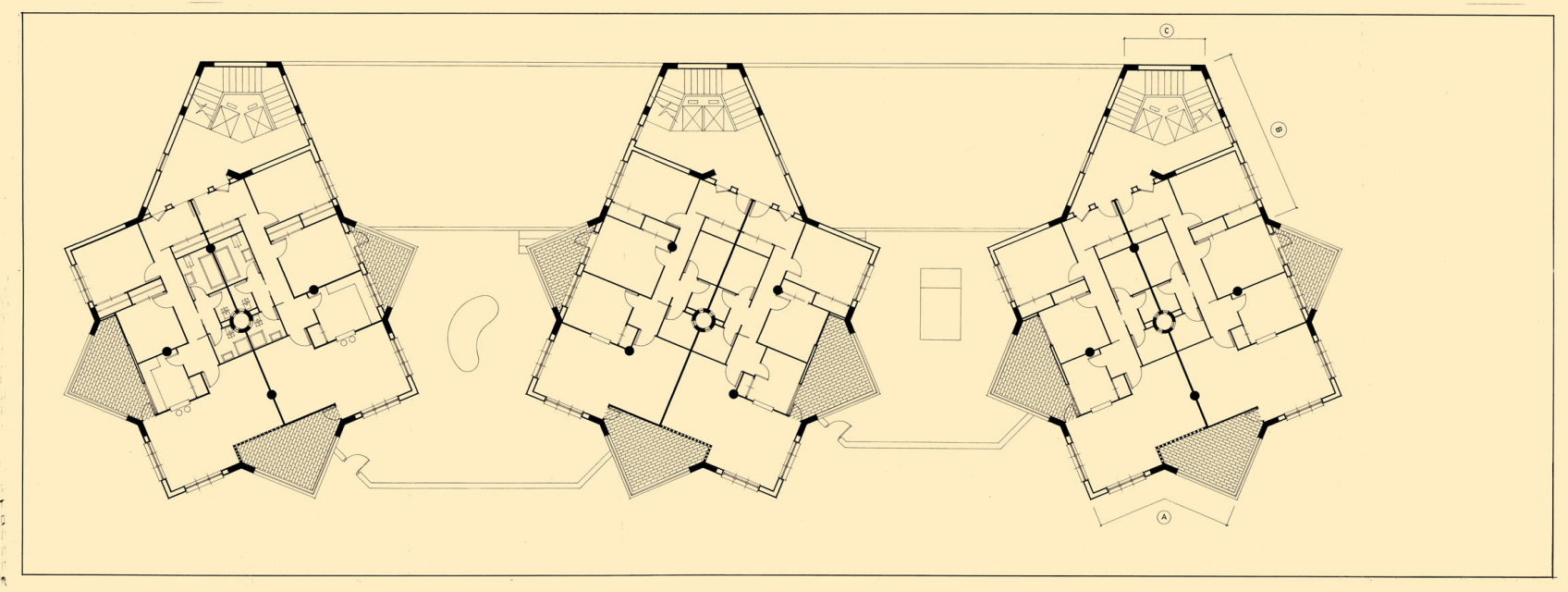

Figura 12. Planta tipo de las Tres Torres del Star Building (segunda versión). (Fuente: ICC).

opuesta al mar, desde el norte y la sombra, donde un recibidor equipado con un armario celebra la entrada. Además, otra puerta permite el paso a un pequeño tendedero ventilado al exterior. El pasillo principal no está enfrentado a la puerta, sino que, en un acto de cortesía e intimidad, se produce (mediante un requiebro) en «L». Ese pasillo, que lleva hasta la luz y el mar, va distribuyendo el dormitorio principal y secundario, además de la cocina, a un lado; y el núcleo húmedo al otro. En el centro geométrico se encuentra un patio oculto de instalaciones de forma circular y, en torno a él, el servicio formado por un aseo con ducha, un WC independiente, y un baño equipado con bañera y lavamanos.

La cocina (de 5,50 $\mathrm{m}^{2}$ ) queda abierta al estar-comedor, y dispone de una ventana al exterior - pero sin acceso a la terraza que comparte con uno de los dormitorios y que sí tiene acceso desde éste- El estar-comedor está compuesto por dos ventanas y acceso a la terraza.

La terraza principal (de 8,40 $\mathrm{m}^{2}$ ), es decir, la que está exactamente en el lado opuesto del acceso y que mira al mar, no tiene la carpintería alineada con el cerramiento de ladrillo, sino que se retranquea un metro, formando la ventana de vidrio una «L», y produciendo el acceso a las terrazas por el lado corto. La simetría de la planta de la torre se rompe, precisamente, en esta terraza, donde uno de los apartamentos disfruta de la totalidad de ella, e invade el espacio que las estrictas leyes de la simetría le otorgarían al apartamento vecino. A cambio, el salón de la terraza invadida disfruta de un acceso a la terraza lateral; quedando, definitivamente, tanto el dormitorio como la cocina sin acceso a ella. Esta terraza lateral será más grande que la del otro apartamento e igualmente la cristalera se retranquearía un metro. La terraza de los dormitorios -en el caso de la casa que disfruta de la terraza principal completa- si está alineado las puertas con el cerramiento, siendo algo menor esta terraza lateral $\left(\right.$ de 4,95 $\left.\mathrm{m}^{2}\right)$.

\section{b) Segunda versión: tres núcleos}

La segunda versión tiene como novedad que cada torre dispone de un núcleo de escaleras propio y dos ascensores, eliminando las pasarelas, y dibujando las tres torres independientes.

Los núcleos de escalera quedan adosados en la zona norte y se dibujan prolongando el lado de uno de los cuadrados con el lado opuesto del cuadrado girado y achaflanando la esquina 
(Figura 12). Así, el alzado posterior del Star-Building queda reducido a 3,50 m que, como se ha comentado y debido a las 11 plantas de altura, subrayan la apuesta por la esbeltez de las Tres Torres.

\section{c) Tercera versión: definitiva}

La versión que definitivamente se construyó, volumétricamente, se asemeja a la segunda. Es en la distribución interior donde encontramos los cambios más significativos. Ahora sí, las dos casas son exactamente idénticas: al dividir la terraza principal por el mismo muro que separa ambos apartamentos. Aunque las viviendas sean iguales, la disposición de las escaleras y el giro de cada planta, hace que la planta no sea simétrica (Figura 13). El núcleo central queda distribuido con un baño completo y un pequeño aseo-lavadero. Y la cocina queda definitivamente incluida en el estar-comedor mediante un mueble-bar formando un cuarto de círculo que se apoya en el cuarto húmedo. $\mathrm{Al}$ final del pasillo distribuidor principal, sendas puertas dan paso para la cocina y el estar-comedor; y éste presenta, además de las dos ventanas, dos terrazas: la frontal correspondiente a la mitad que comparten ambas casas -pero separada por un tabique de ladrillo-, y otra lateral con acceso, y que comparte con uno de los dormitorios que también accede a dicha terraza. Se produce así, una circulación circular desde el estar-comedor al dormitorio, a través de la terraza que comparten, y mediante el pasillo interior. Según sea la plan- ta par o impar, aparece -o no- uno de los pilares circulares centrales dispuesto en el salón-comedor. Los otros tres, o bien quedan dentro de los armarios, o bien en el muro que separa ambos apartamentos. En la (Figura 13) se puede ver grafiado a lápiz la posición de esos pilares, según cada planta.

\section{VENUSTAS O EL PLACER AUSTERO}

El Sur invita a disfrutar de la vida sin renunciar al placer de lo cotidiano: guarecerse a la sombra de una terraza, mirar el mar desde una atalaya, leer un libro con la suave brisa, o refrescarse en una alberca (Figura 14). La arquitectura de Cassinello, mediterránea como se ha comentado, ha sabido reconciliar el placer con la austeridad de una forma natural. Seguramente ahí resida la felicidad y el éxito -también la Arquitectura-: en tener la habilidad de multiplicar el placer con actos sencillos (11).

Fernando Cassinello no busca la belleza en sus obras de arquitectura (venustas): la encuentra como consecuencia de descubrir el exacto punto de equilibrio que une el pragmatismo (utilitas) y la sinceridad estructural (firmitas). Es decir, lo que él llamaba «Arquitectura auténtica» (12): la que recibe con agrado las huellas del proceso de construcción y su hermosa imperfección; la radical, es decir, la que busca en la raíz; la que renuncia de lo superfluo; la que sirve de silente escenario para que el hombre se entregue a la felicidad casi

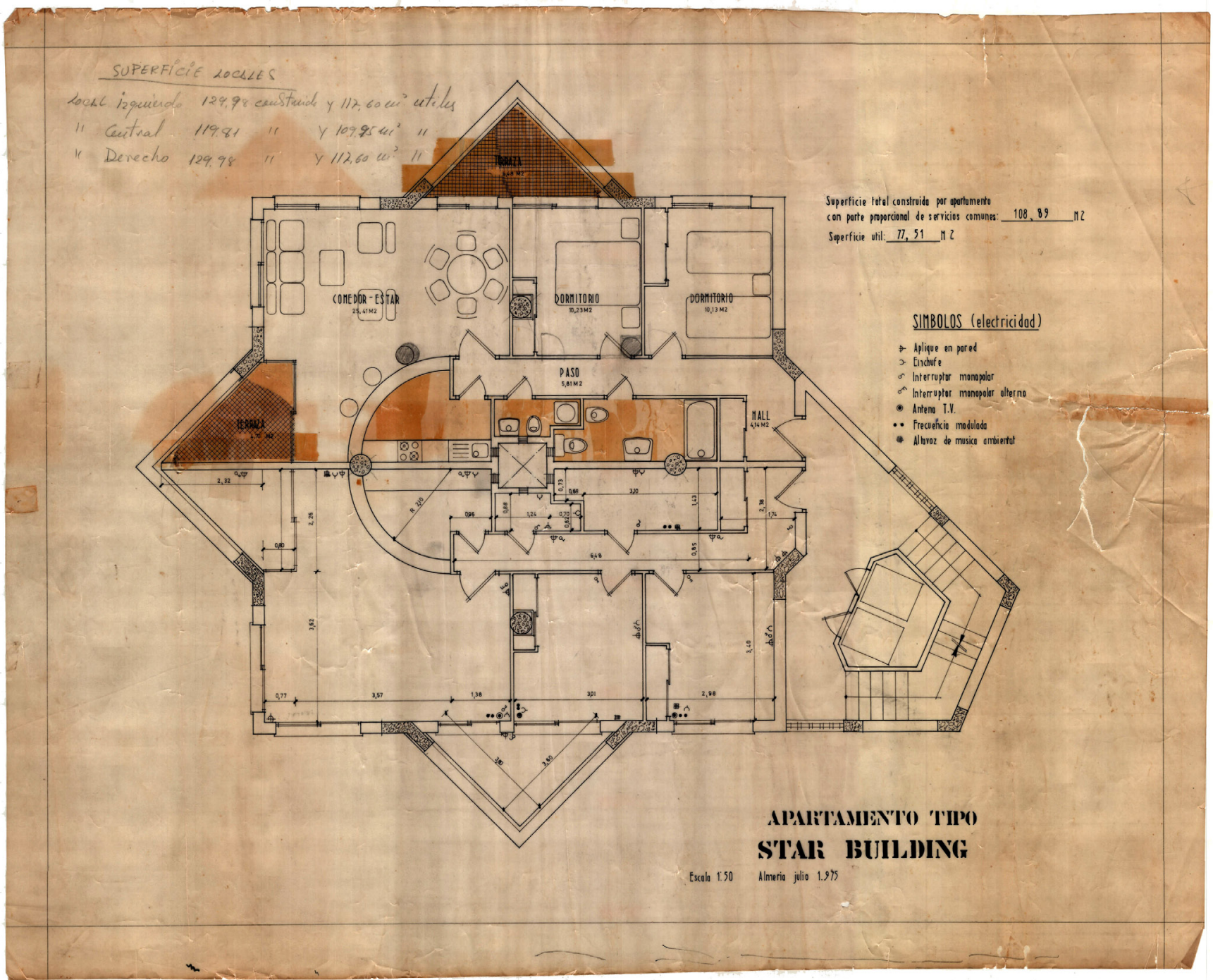

Figura 13. Planta tipo de las Tres Torres del Star Building (tercera y definitiva versión). (Fuente: María del Mar Samper). 


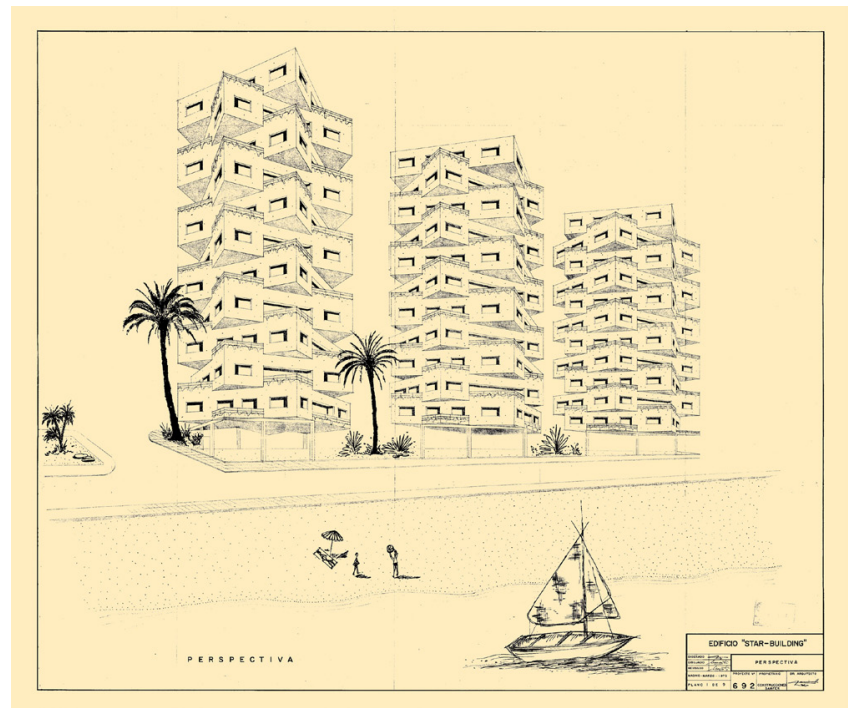

Figura 14. Perspectiva exterior desde el mar de las Tres Torres del Star Building (primera versión). (Fuente: Archivo Municipal del Ayuntamiento de Almería).

sin darse cuenta; y la que hilvana un discurso Global con los medios y peculiaridades de cada pueblo.

\section{CONCLUSIÓN. EPÍLOGO PROFESIONAL}

Vita brevis, ars longa. La vida breve siempre atormentó a los creadores cuyo afán procreador no saciaba su querencia de tiempo para seguir emprendiendo proyectos y obras. Y sin embargo, esa muerte cercana le da cierta intensidad a la propia vida. Un creador no siempre es consciente de cuál será su última obra. La muerte es siempre una sorpresa, una victoria y un fracaso.

Fernando Cassinello certifica el final de la obra del Star-Building, el 23 de julio de 1975. El colegio de Arquitectos sella el visado el 19 de agosto de 1975: exactamente el mismo día que fallece en Madrid, de forma prematura e inesperada, a los 48 años de edad. Se trata, por tanto, de su última obra. No pretendía serlo - de hecho, dejó decenas de proyectos a medias-, y por tanto es difícil extraer conclusiones sobre ese último acto. Desde luego, el autor no intentó depositar en el Star Building, una lección definitiva. Todo lo contrario, las Tres Torres son el fruto del coraje y la intensidad que aplicaba en todos los proyectos, con independencia del cliente, presupuesto o localización.

Lejos de la casualidad, el Star Building es un digno epílogo profesional que resume, punto por punto, toda su trayectoria. Es una obra que rezuma experiencia y traspira frescura.

Así son y ahí quedan las Tres Torres, como testigo silencioso del rumor de las olas y del silbido del viento. Y su presencia, todavía hoy, puede considerarse como la obra de arquitectura más hermosa construida en todo el paseo marítimo de Almería. Además, son la huella triplicada de Fernando Cassinello Pérez: el arquitecto almeriense, de todos los tiempos, que más lejos ha llegado.

\section{REFERENCIAS}

(1) Ponce-Ortiz de Insagurbe, M., Sánchez-Sánchez, J. (2006). Construir el siglo XX con Informes de la Construcción. Índice de índices. Madrid: Consejo Superior de Investigaciones Científicas.

(2) Pérez-Escolano, V., Pastor-Rodríguez, L., Martínez-Rodríguez, A., Fernández-Martínez, L., Fernández-Martínez, C. M. (2006). Guía de Arquitectura de Almería, p. 215. Almería-Sevilla: Colegio de Arquitectos de Almería y Consejería de Obras Públicas y Transportes de la Junta de Andalucía.

(3) Cassinello, F. (1970). Dos hoteles en Almería: Gran hotel Almería y Alcazaba Gran Hotel. Informes de la Construcción, 23(220): 5-28.

(4) Orejudo, A., Santiago, J. A., Villanueva, E. (2003). Desengaño veraniego. En La Arquitectura del Sol_Sunland Architecture (p. 282). Barcelona: COAC, COAAL,

(5) Cassinello, F. (1974). Construcción Hormigonería. Madrid: Editorial Rueda e Instituto Juan de Herrera.

(6) Ruiz-García, A. (1998). Ciudad Jardín, Almería, 1940-1947: Guillermo Langle Rubio. En Archivos de Arquitectura: España Siglo $X X$, vol. 8. Barcelona: Colegio Oficial de Arquitectos de Almería.

(7) Valero-Ramos, E. (2008). La Universidad Laboral de Almería: 1971-1974: J. Cano Lasso, A. Campo Baeza, M. Martín, A. Más. En Archivos de Arquitectura: España Siglo XX, vol. 15. Barcelona: Colegio Oficial de Arquitectos de Almería.

(8) Cassinello-Pérez, F. (1956). Hormigón, material noble de hoy. Informes de la Construcción, 9(86).

(9) Cassinello-Pérez, F. (1963). Adherencia de hormigones y morteros a materiales cerámicos de construcción. Boletín de la sociedad española de Cerámica y Vidrio, 2(4): 233-249.

(10) Cassinello-Pérez, F. (1960). Los amigos del ladrillo. Monografía IETCC, $\mathrm{n}^{0}$ 205. Madrid: Patronato Juan de la Cierva Consejo Superior de Investigaciones Científicas.

(11) García-Sánchez, J.F. (2012). El Sur: placer austero. En La Euritmia (pp. 46-47). Madrid: Ed. Mairea Libros.

(12) Cassinello-Pérez, F. (1961). Eduardo Torroja. Cuadernos de Arquitectura, 46. 